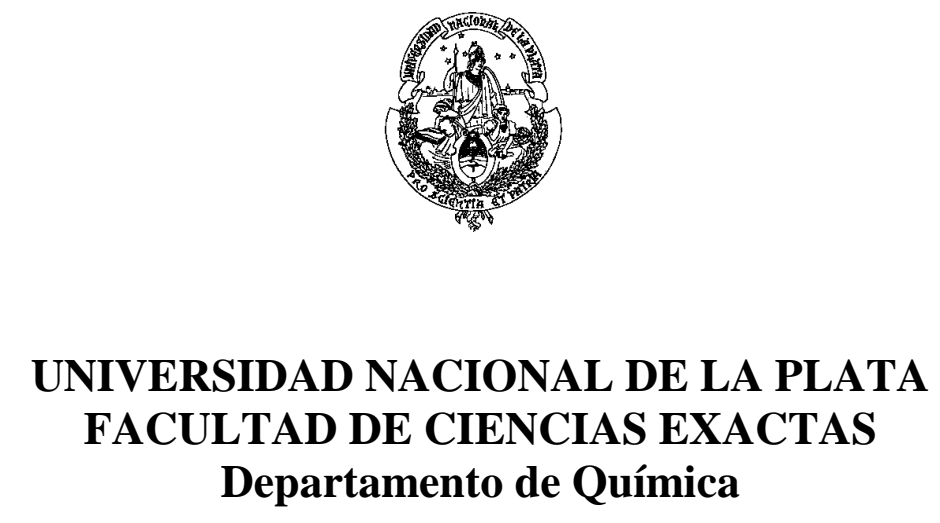

\title{
ESTUDIO TEÓRICO Y DE FOTÓLISIS FLASH CON LÁSER DE LA CINÉTICA DE REACCIONES DE RADICALES FLUORADOS Y FLUOROSULFURADOS EN FASE GASEOSA
}

\section{María Eugenia Tucceri}

Lugar de trabajo: Instituto de Investigaciones Fisicoquímicas Teóricas y Aplicadas, INIFTA.

Director: Dr. Carlos Jorge Cobos

Co-Director: Dra. Adela Ester Croce

Trabajo de Tesis presentado para optar al título de Doctor de la Facultad de Ciencias Exactas 